\title{
ENHANCEMENT OF THE LEUKOCYTE-ENDOTHELIAL CELL INTERACTION IN COLLECTING VENULES OF SKELETAL MUSCLE BY PROTAMINE
}

Helmut Habazettl, MD ${ }^{\mathrm{a}}$

Vladimir Martinek, $\mathrm{MD}^{\mathrm{a}}$

Brigitte Vollmar, $\mathrm{MD}^{\mathrm{a}}$

Peter Conzen, $\mathrm{MD}^{\mathrm{b}}$
Objective: A transient but severe systemic leukopenia regularly occurs after the antagonization of heparin by protamine in patients and in animals. The aim of the present study was to investigate the site and mechanisms of white blood cell retention during this transient leukopenia by studying the leukocyte-endothelial cell interaction in skeletal muscle venules. Methods: Syrian golden hamsters were equipped with a dorsal skinfold chamber for intravital fluorescence microscopy and arterial and venous catheters for drug infusion, blood pressure measurement, and blood sampling. Microhemodynamic parameters and leukocyte-endothelial cell interactions were observed in one single collecting venule per animal after intravenous infusion of saline solution (control, $n=10$ ), of protamine $(n=9)$, and after infusion of heparin followed by either intravenous protamine $(n=9)$ or intraarterial protamine $(n=9)$. Results: All parameters remained unchanged in the control group. Whereas venular diameters remained unchanged, protamine transiently increased arterial blood pressure and venular erythrocyte velocity in all groups. Systemic leukocyte counts and the venular leukocyte discharge concentration decreased concurrently after protamine administration by about $60 \%$ to $70 \%$ at 2 minutes while the fraction of rolling leukocytes and the number of adherent leukocytes remained unchanged. Two and one-half minutes later, systemic leukocyte counts and venular discharge concentrations normalized while the fraction of leukocytes rolling slowly along or adhering firmly to the venular endothelial wall increased considerably and similarly in all groups receiving protamine. Myeloperoxidase (an indicator of polymorphonuclear leu* kocytes) determination in 20 separate hamsters 2 minutes after protamine infusion revealed increased myeloperoxidase activity exclusively in the Iungs. Conclusion: The response of leukocytes to protamine infusion with or without prior heparinization is biphasic: initial retention of leukocytes in the lungs is followed by enhanced leukocyte-endothelial cell interaction in the systemic circulation. ( $J$ Thorac Cardiovasc Surg 1997;113:784-91)
E nhanced interactions between leukocytes and the endothelium are considered a crucial early step in the process of leukocyte emigration and the subsequent inflammatory and immune responses. ${ }^{1}$

From the Institute for Surgical Research ${ }^{a}$ and Institute for Anesthesiology, ${ }^{\mathrm{b}}$ Klinikum Grosshadern, University of $\mathrm{Mu}$ nich, Munich, Germany.

Received for publication July 5, 1996; revisions requested Oct. 11, 1996; revisions received Dec. 10, 1996; accepted for publication Dec. 11, 1996.

Address for reprints: Helmut Habazettl, MD, Institute for Surgical Research, University of Munich, Marchioninistr. 15, 81366 Munich, Germany.

Copyright (C) 1997 by Mosby-Year Book, Inc.

$0022-5223 / 97 \$ 5.00+0 \quad \mathbf{1 2 / 1 / 7 9 7 8 3}$
Leukocyte-endothelial cell interaction is implicated in numerous pathogenetic mechanisms such as adult respiratory distress syndrome, transplant rejection, atherosclerosis, and reperfusion injury. The receptor proteins on the surface of endothelial and white blood cells ${ }^{1}$ are thought to mediate at least part of these phenomena. Conformational changes, enhanced expression of preformed proteins on cell surfaces, as well as de novo synthesis of receptor proteins seem to occur during the activation of different receptor types. ${ }^{1-3}$

Pharmacologic interventions have also been associated with altered leukocyte-endothelial cell interaction. Tangelder and Arfors ${ }^{4}$ found that polyanions and polycations diminished the interaction between 
leukocytes and the endothelium of mesenteric venules. Among these substances, heparin and protamine are used clinically for blood anticoagulation and for the subsequent reversal of the anticoagulative effects of heparin, respectively. In human beings, the antagonization of heparin by protamine, which is routinely performed in cardiac surgery after weaning from cardiopulmonary bypass, can result in pulmonary hypertension and systemic hypotension, as well as leukopenia, thrombopenia, activation of the complement cascade, and release of vasoactive eicosanoids (thromboxane $A_{2}$, prostacyclin)..$^{5-7}$ In animal experiments, the hemodynamic effects could be attenuated by a thromboxane synthetase inhibitor $^{8}$ and a complement antagonist. ${ }^{9}$ Pulmonary hypertension was completely blocked by cyclooxygenase inhibitors ${ }^{10}$ and a thromboxane receptor antagonist, ${ }^{11}$ whereas the acute leukopenia caused by protamine remained virtually unaffected by these interventions. Pretreatment with dimethylthiourea, a free radical scavenger, attenuated the thromboxane release and pulmonary vasoconstriction after protamine in sheep, ${ }^{8}$ but not in pigs. ${ }^{12}$ Also, data collected from leukopenic pigs suggest that thromboxane release and hemodynamic effects after heparin/protamine administration are not mediated by circulating leukocytes. ${ }^{13}$ Thus numerous investigators described a transient leukopenia after protamine; its meaning for the humoral and hemodynamic responses to protamine, however, remains unclear. Although several intravascular activators of leukocytes induced white blood cell retention and tissue damage mainly in the lungs (reviewed by J. C. $\mathrm{Hogg}^{14}$ ), the site and mechanism of leukocyte retention during the protamine-induced leukopenia have not yet been determined.

Because leukocyte adhesion contributes to reperfusion damage after cardiac ischemia, ${ }^{15,}{ }^{16}$ we characterized the heparin/protamine-induced leukocyte activation by direct in vivo observation after injection of heparin, protamine, and the interaction of heparin with protamine using the dorsal skinfold chamber in the Syrian golden hamster. Margination of leukocytes in other organs was investigated by myeloperoxidase (MPO) determination.

\section{Methods}

Animal model and preparation. For intravital fluorescence microscopy, we used the dorsal skinfold preparation in Syrian golden hamsters. ${ }^{17}$ This model permits the microscopic quantification of leukocyte-endothelial cell interaction, vessel diameters, and erythrocyte velocity in postcapillary venules of a thin-striated skin muscle within the chamber tissue. All animals received humane care in compliance with the "Principles of Laboratory Animal Care" formulated by the National Society for Medical Research and the "Guide for the Care and Use of Laboratory Animals" prepared by the Institute of Laboratory Animal Resources and published by the National Institutes of Health (NIH Publication No. 86-23, revised 1985). The experimental preparation used in this study has been described in detail. ${ }^{7}$ In brief, 6- to 8-week-old Syrian golden hamsters were anesthetized (pentobarbital, $60 \mathrm{mg} / \mathrm{kg}$ intraperitoneally) and two titanium frames were implanted so as to sandwich the extended double layer of the dorsal skin. In a circular area of $15 \mathrm{~mm}$ in diameter, one layer was completely removed; the remaining layer, consisting of epidermis, subcutaneous tissue, and a thin striated muscle, was covered with a transparent glass coverslip incorporated into one of the frames. Fine polyethylene catheters were implanted into the jugular vein and the carotid artery, passed subcutaneously to the dorsal side of the neck, and sutured to the titanium frames. The animals tolerated the dorsal skinfold chambers well and showed no signs of discomfort. Namely, no effects on sleeping habits and weight gains were observed.

Intravital video microscopy. Two to 3 days after the preparation, the animals were sedated with pentobarbital $(15 \mathrm{mg} / \mathrm{kg}$ intravenously) and placed under a microscope (Orthoplan, Leitz, Wetzlar, Germany). The carotid artery catheter was connected to a pressure transducer (Gould Instruments, Oxnard, Calif.) for continuous monitoring of arterial pressure. A $\times 25$ water immersion objective (Leitz) was used to select one postcapillary or collecting venule with 30 to $50 \mu \mathrm{m}$ in diameter. These vessels are considered to be the major site of leukocyte-endothelium interaction in response to several stimuli. ${ }^{2,18}$

Autologous erythrocytes were stained with fluorescein isothiocyanate (FITC) in vitro as described previously ${ }^{19}$ and injected $(0.1 \mathrm{ml}$, hematocrit value $30 \%)$ intravenously 10 minutes before the experiments. For visualization of leukocytes, the in vivo fluorescent marker rhodamine $6 \mathrm{G}$ (0.1 ml, $40 \mathrm{mg} / \mathrm{ml}$; Merck, Darmstadt, Germany) was injected intravenously 5 minutes before the experiments and every 10 minutes thereafter. Epiillumination was achieved with a 75-W Xenon lamp attached to a Ploemopak illuminator with an $\mathrm{N}_{2}$ and an $\mathrm{L}_{3}$ filter block (Leitz). Because of the different excitation and emission spectra of rhodamine $6 \mathrm{G}(530$ to $560 \mathrm{~nm},>580 \mathrm{~nm})$ and FITC ( 450 to $490 \mathrm{~nm},>515 \mathrm{~nm}$ ), this system allowed for the separate visualization of erythrocytes and leukocytes by switching from the $\mathrm{N}_{2}$ to the $\mathrm{L}_{3}$ filter block, respectively. The microscopic images (Camera Hamamatsu C2400, Hamamatsu City, Japan) were stored on videotape and evaluated off-line by frame-to-frame analysis. Vessel diameters, erythrocyte center line velocity $\left(V_{\text {ery }}\right)$, leukocyte flux $\left(\mathrm{FLUX}_{\mathrm{Ieu}}\right)$, and leukocyte velocities $\left(\mathrm{V}_{\text {leu }}\right)$ were determined. The venular leukocyte discharge concentration $\left(\mathrm{LEU}_{\mathrm{ven}}\right)^{18}$ was calculated by the formula:

$$
\operatorname{LEU}_{\mathrm{ven}}=\mathrm{FLUX}_{\mathrm{leu}} / \mathrm{FLUX}_{\mathrm{vol}}(1 / \mu \mathrm{l})
$$

where FLUX ${ }_{\mathrm{vol}}$ (volume flux) was estimated by $\mathrm{V}_{\text {ery }}$ times vessel cross-sectional area and divided by 1.6. For a single 
leukocyte the adhesion index (AQ) was calculated from its individual velocity $\left(\mathrm{V}_{\text {lent }}\right)$ and $\mathrm{V}_{\text {ery }}$ :

$$
\mathrm{AQ}=\left(\mathrm{V}_{\text {ery }}-\mathrm{V}_{\text {leu }}\right) / \mathrm{V}_{\text {ery }}
$$

The degree of interaction of a single leukocyte with the endothelium was estimated from its AQ: not interacting cells, $\mathrm{AQ}=0.0$ to 0.5 ; rolling leukocytes (primary leukocyte-endothelial cell interaction) $\mathrm{AQ}=0.6$ to 0.9 ; and adherent leukocytes (secondary leukocyte-endothelial cell interaction) $\mathrm{AQ}=1.0$. Rolling leukocytes are given as percentage of the total number of cells passing through the observed vessel within the observation period. Adherent leukocytes are given as number per square millimeter of endothelial surface area as calculated from vessel diameter and length of the vessel segment studied (150 to $250 \mu \mathrm{m}$ ).

MPO activity in tissue. To study the organ distribution of neutrophils at the nadir of peripheral leukocyte counts, that is, the peak of margination, we determined MPO activity in the lungs, liver, spleen, bowel, skeletal muscle, and skin. Twenty separate hamsters were anesthetized (pentobarbital, $60 \mathrm{mg} / \mathrm{kg}$ intraperitoneally), equipped with a jugular venous catheter, and heparinized $(350 \mathrm{IU} / \mathrm{kg})$. Four minutes later either protamine $(6 \mathrm{mg} / \mathrm{kg}, n=10)$ or, in control animals $(n=10)$, an equal volume of saline solution was injected. After 2 minutes the thorax was opened and the hearts quickly excised to induce instant circulatory arrest. The aforementioned organs were removed, cleared of connective tissue, and stored at $-70^{\circ} \mathrm{C}$. MPO was extracted as described by Schierwagen, BylundFellenius, and Lundberg. ${ }^{20}$ MPO activity was determined photometrically by the hydrogen peroxide-dependent oxidation of 3,3',5,5'tetramethylbenzidin at $655 \mathrm{~nm}$ and $25^{\circ} \mathrm{C}$. A kinetic method of calculating activity was used, and 1 unit of MPO activity was defined to alter extinction by $1.0 / \mathrm{min}$.

Experimental protocol. After injection of FITC-labeled erythrocytes and rhodamine $6 \mathrm{G}$, the first of a total of nine video sequences was recorded ( $t=-7$ minutes). Each sequence contained 10 seconds of erythrocyte, 60 seconds of leukocyte, and again 10 seconds of erythrocyte observation via the respective filter blocks. At $t=-4$ minutes, heparin (350 IU/kg, porcine, Heparin-Natrium, Braun, Melsungen, Germany) was injected intravenously, and at $t=0$ minutes, protamine $(6 \mathrm{mg} / \mathrm{kg}$, salmine, Protaminsulfat Novo, Novo Industrie, Mainz, Germany) was injected intravenously. Video recordings were obtained after heparin injection ( $t=-3$ minutes) and after protamine injection $(t=0.5,2,4.5,7,10,13$, and 23 minutes). Arterial blood samples $(80 \mu \mathrm{l})$ were drawn at $t=-1,2,5$, 15 , and 25 minutes, and the number of leukocytes was determined in a $0.01 \mu \mathrm{l}$ aliquot in a counting chamber (Neubauer, Zeiss, Jena, Germany).

Study groups. The animals were arbitrarily assigned to four different groups so that two or more experiments performed on a single day were designated to different groups. Also, experiments from all four groups were present from the onset to the end of the total study period to avoid time-dependent influences on the results. So that the stability of the preparation could be evaluated, control animals (control group, $n=10$ ) received equal volumes of saline solution instead of heparin and protamine. The effects of protamine alone were studied in a group in which saline solution was given at $t=-4$ minutes and protamine at $t=0$ minutes (protamine group, $n=9$ ). In the third group the clinically established procedure of antagonization of heparin by intravenous injection of protamine was used ( $\mathrm{HPv}$ group, $n=9$ ). To assess the possible influence of the site of leukocyte activation on their interaction with the endothelium, we injected protamine into the ascending thoracic aorta via the carotid artery catheter in the animals of the fourth group ( $\mathrm{HPa}$ group, $n=9$ ).

Statistics. All data given are means \pm standard error of the mean. Effects of heparin or protamine injections within the groups were evaluated by the Friedman rank analysis of variance. When these test results indicated significant differences within a group, single measurements after heparin or protamine injection were compared against the preceding baseline data by the Wilcoxon matched pairs test. Differences among study groups were evaluated by the Kruskal-Wallis test, followed by the U test to detect the groups actually different from each other. Statistical significance was set at $p<0.05$.

\section{Results}

Hemodynamics. Hemodynamic parameters remained unchanged in the control group throughout the experiments. Baseline values of mean arterial pressure were $104 \pm 7,103 \pm 9,98 \pm 8$, and $98 \pm 7$ $\mathrm{mm} \mathrm{Hg}$ in the control, protamine, $\mathrm{HPv}$, and $\mathrm{HPa}$ groups, respectively, and transiently $(<4$ minutes) increased by $21 \pm 7,18 \pm 7$, and $26 \pm 8 \mathrm{~mm} \mathrm{Hg}$ in the protamine, $\mathrm{HPv}$, and $\mathrm{HPa}$ groups 2 minutes after protamine. Diameters of the venules studied (one per experiment) ranged from $40.3 \pm 1.5(\mathrm{HPv}$ group) to $45.3 \pm 2.6$ (control group) $\mu \mathrm{m}$ and did not change throughout the experiments. Erythrocyte velocity increased from baseline values between $734 \pm 71$ ( $\mathrm{HPv}$ group) and $938 \pm 101 \mu \mathrm{m} / \mathrm{sec}$ (control group) by $21 \%$ to $42 \%$ immediately after protamine but returned to baseline values within 2 minutes and remained unchanged thereafter. Hemodynamic parameters remained unchanged after heparin injection in all study groups.

Leukocyte concentrations. The number of leukocytes in arterial blood samples, as well as the venular leukocyte discharge concentration, remained unchanged after heparin but decreased considerably, by $60 \%$ to $71 \%$, immediately after protamine, reaching the nadir after 2 minutes (Figs. 1 and 2). Both parameters were restored to baseline values or exceeded baseline values within 10 to 15 minutes after protamine infusion.

Fraction of rolling leukocytes. At baseline, 20\% to $25 \%$ of nonadherent leukocytes were defined as rollers (adhesion index: 0.6 to 0.9 ; Fig. 3). Injection 


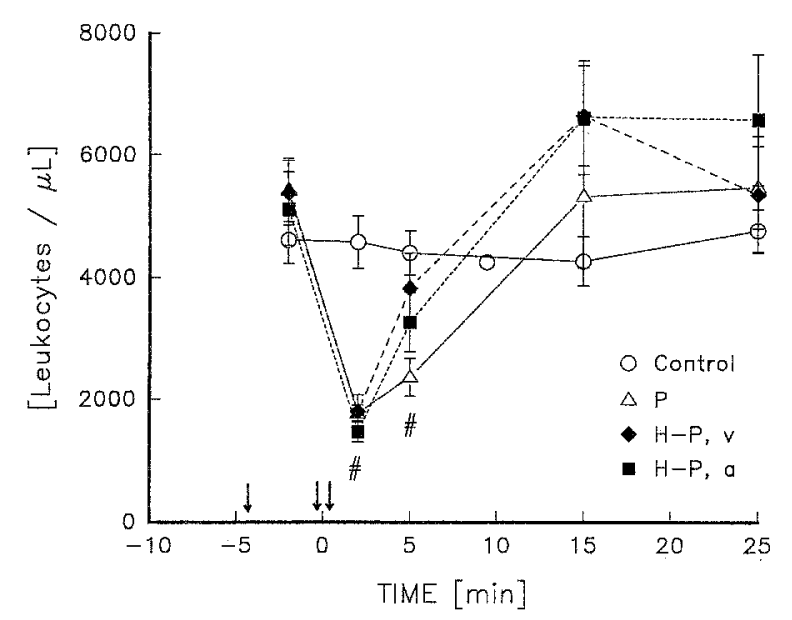

Fig. 1. Systemic leukocyte counts from arterial blood were determined 1 minute before and $2,5,15$, and 25 minutes after protamine injection $(\downarrow \downarrow)$. Heparin was given 4 minutes before protamine $(\downarrow)$. Study groups: Control animals $(n=10)$ received neither heparin nor protamine but equal volumes of saline solution; the protamine group (group $P, n=9$ ) was given saline solution at -4 minutes and protamine at time zero. H-P, $v$ animals $(n=9)$ received heparin and protamine, both intravenously; H-P, a hamsters $(n=9)$ were given an intravenous injection of heparin, followed by protamine administration into the aorta. All data are mean \pm standard error of the mean; \#p<0.05, all experimental groups versus the control group.

of heparin caused a slight but significant decrease of rolling leukocytes in both $\mathrm{HPv}$ and $\mathrm{HPa}$ animals. Within the first 2 minutes after protamine administration, that is, at a time when the number of leukocytes discharged to the venules under observation was diminished, the fraction of rolling leukocytes remained at the low pre-protamine levels. Only at 4.5 minutes after protamine was there an increase in the percentage of rollers, to about $200 \%$ of baseline values. Primary, intermittent leukocyteendothelial cell interaction, as expressed by the proportion of rolling cells, remained increased until 13 minutes after protamine. No difference between the study groups that received protamine was observed. In the control group, primary leukocyteendothelial cell interaction in the investigated venules remained unchanged throughout the experiments.

Adherent leukocytes. At baseline, $44 \pm 33,15 \pm$ $12,44 \pm 35$, and 0 adherent leukocytes per square millimeter of venular endothelial surface area were encountered in the control, protamine, $\mathrm{HPv}$, and

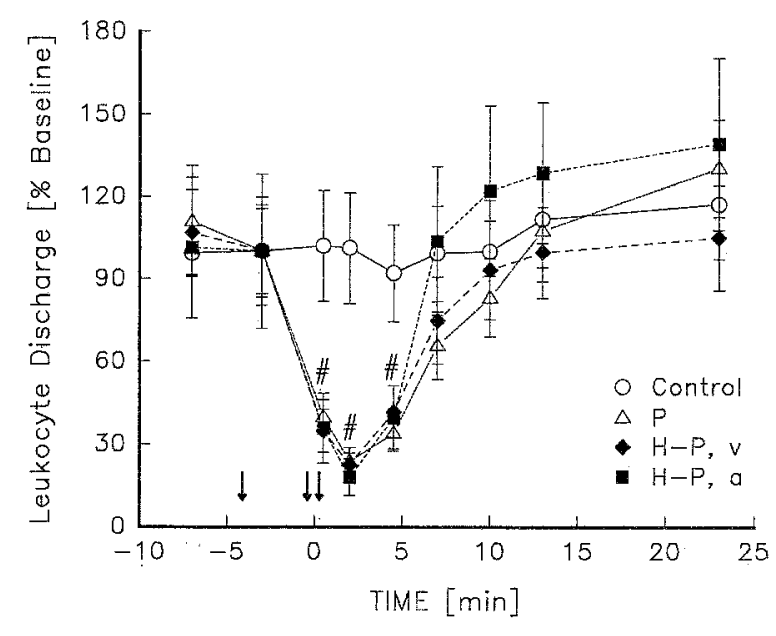

Fig. 2. The leukocyte discharge concentration, that is, an estimation of the concentration of leukocytes in the blood passing the venules under investigation (one per animal), is given in percent of baseline immediately before protamine. $\downarrow$, Injection of heparin; $\downarrow \downarrow$, injection of protamine. Microvascular data were obtained in one venule of each hamster before heparin $(-7)$, after heparin $(-3)$, and $0.5,2,4.5,7,13$, and 23 minutes after protamine. For abbreviations of study groups see Fig. 1. All data are mean \pm standard error of the mean; $\# p<0.05$, all experimental groups versus the control group.

$\mathrm{HPa}$ groups, respectively. Heparin reduced the number of adherent leukocytes in HPv hamsters to zero. Immediately after protamine, the number of adherent leukocytes remained low, commenced to increase after 2 to 4.5 minutes, and reached a maximum of $164 \pm 113,153 \pm 75$, and $249 \pm 134$ cells $/ \mathrm{mm}^{2}$ in the protamine, $\mathrm{HPv}$, and HPa groups, respectively, at 4.5 or 7.5 minutes after protamine. Between 10 and 13 minutes after protamine, the number of adherent leukocytes had returned to baseline values and did not change thereafter (Fig. 4).

MPO organ distribution. Substantial amounts of MPO in control animals were detected in lungs $(1.84 \pm 0.28 \mathrm{U} / \mathrm{gm})$, liver $(0.62 \pm 0.07 \mathrm{U} / \mathrm{gm})$, spleen $(4.31 \pm 1.00 \mathrm{U} / \mathrm{gm})$, and intestine $(0.91 \pm 0.23$ $\mathrm{U} / \mathrm{gm})$, but not in skin or skeletal muscle. Two minutes after heparin reversal by protamine, a significant increase of MPO activity occurred exclusively in the lungs (Fig. 5).

\section{Discussion}

The present study shows that protamine in both heparinized and untreated hamsters enhances the 




Fig. 3. The number of leukocytes rolling along the endothelium of the venules under investigation (one per animal) is given in percent of all nonadherent leukocytes. $\downarrow$, Heparin; $\downarrow \downarrow$, protamine injection. For definition of study groups see Fig. 1. All data are mean \pm standard error of the mean; ${ }^{*} p<0.05, \mathrm{H}-\mathrm{P}, \mathrm{v}$ versus the control group; $\# p<0.05$, all experimental groups versus the control group.

leukocyte-endothelial cell interaction in collecting venules of striated skin muscle. A biphasic response to protamine bolus injections was detected: during the first 1 to 2 minutes the venular leukocyte discharge concentration decreased, with leukocytes marginating in the lungs, whereas the interaction of the circulating leukocytes with the endothelium of peripheral venules appeared unaltered; at 4.5 minutes after protamine injections, the leukocyte discharge concentration commenced returning to baseline values, whereas rolling and firm adhesion of leukocytes in collecting venules increased.

In vivo microscopic observation of the leukocyteendothelial cell interaction requires surgical exteriorization of the tissue. The models most commonly used are the hamster skinfold or cheek pouch preparation, hamster or rat cremaster muscle, rat or rabbit mesentery, and the surfaces of solid organs such as brain or heart. Whereas stimuli like ischemia and reperfusion damage or chemotactic agents provoked similar reactions in all these models, only the permanent hamster skinfold chamber allows for microcirculatory studies in unanesthetized animals without acute surgical trauma of the tissue under investigation.

In the hamster skinfold preparation in this and in previous studies, ${ }^{21}$ baseline leukocyte-endothelial cell interaction (5\% to $25 \%$ rolling leukocytes) was

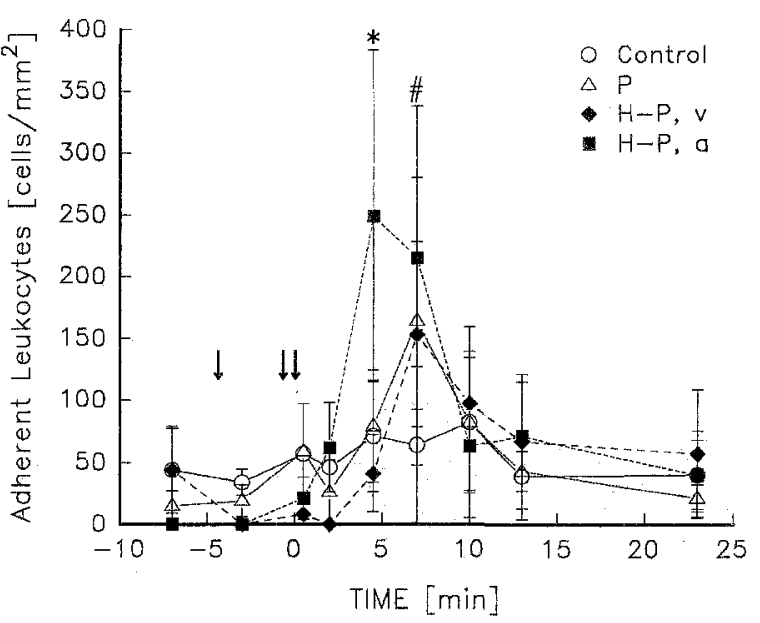

Fig. 4. The number of leukocytes adhering to the endothelium of the venules under investigation (one per ani$\mathrm{mal}$ ) is given in cells per square millimeter of endothelial surface area. $\downarrow$, Heparin; $\downarrow \downarrow$, protamine injection. For definition of study groups see Fig. 1. All data are mean \pm standard error of the mean; ${ }^{*} p<0.05, \mathrm{H}-\mathrm{P}$, a versus the control group; $\# p<0.05$, all experimental groups versus the control group.

present also during control conditions. Rolling and sticking of leukocytes remained constant in control animals throughout the study, suggesting that our experimental setup and the repeated microscopy did not alter leukocyte-endothelial cell interaction. Baseline leukocyte rolling was also reported for an acute preparation of rabbit mesentery (12 to 188 leukocytes per venule and minute). ${ }^{4}$ Since in human beings, as well as in all animals studied previously, including pigs, ${ }^{10,11,13}$ sheep, ${ }^{8}$ dogs ${ }^{22}$ rabbits, ${ }^{23}$ and rats, ${ }^{24}$ protamine with or without prior application of heparin had caused transient leukopenia, we performed pilot studies and detected a similar decrease of the leukocyte count in hamsters 2 minutes after protamine injection. To eliminate the effect of decreased systemic blood leukocyte counts on the results, we expressed all data concerning numbers of rolling leukocytes as percent of total numbers of leukocytes passing the observed vessels. In addition, the venular discharge concentration of leukocytes, that is, the number of leukocytes in the blood delivered to the venules under investigation, was estimated. The transient decrease of the leukocyte discharge concentration after protamine occurred in parallel with the decrease of the leukocyte count in arterial blood.

The effects of protamine, heparin, and several negatively charged macromolecules on the leuko- 
cyte behavior in the rabbit mesentery microcirculation have been studied previously. ${ }^{4}$ Inhibition of the leukocyte-endothelial cell interaction by heparin could be confirmed for venules of striated muscle in the present study. However, we were unable to reproduce the findings of Tangelder and Arfors ${ }^{4}$ in rabbits-that the polycation protamine had a similar inhibiting effect on the rolling of leukocytes as the negatively charged sulfated polysaccharides. In the present study, protamine clearly increased rolling and sticking of leukocytes. Species differences do most certainly not account for this discrepancy, because profound transient leukopenia after protamine or heparin/protamine has been described in rabbits as well. ${ }^{23}$ Another explanation seems more likely: Tangelder and Arfors ${ }^{4}$ used the transillumination technique allowing for the visualization of slowly moving (i.e., rolling and sticking) leukocytes only. Thus the absolute number of leukocytes interacting with the endothelium was determined but could not be related to the total number of cells entering the observed venule. This has no influence on the results unless severe changes of the leukocyte discharge concentration occur, as was the case in our study after protamine. The authors accounted for the potential shortcoming of their technique by monitoring systemic leukocyte counts and reported stable cell counts during the first 2 hours of their studies. However, the exact time course of blood sampling for leukocyte count is not clear from the study protocol, and it seems likely that the transient (2- to 3-minute) leukopenia after protamine, which occurs also in the rabbit, ${ }^{23}$ was not covered by their protocol. Thus the decrease of the rolling leukocytes after protamine in Tangelder and Arfors' study ${ }^{4}$ might reflect the decrease of the leukocyte discharge concentration, which has not yet been shown to occur during the protamine reaction.

In all three groups that received protamine, systemic leukocyte counts, leukocyte discharge concentration, and rolling of leukocytes were altered comparably. Thus the increased activation of the leukocyte-endothelial cell interaction after protamine in hamsters seems to occur independently of complement activation or release of thromboxane $A_{2}$, which has been found only in heparinized animals. $8,11,25$ Also, pretreatment of animals with a thromboxane $\mathrm{A}_{2}$ receptor antagonist abolished the hemodynamic effects of protamine, but not the leukopenia. ${ }^{11}$ In species susceptible to complement activation, thromboxane $A_{2}$ release and pulmonary hypertension after heparin/protamine-induced leu-

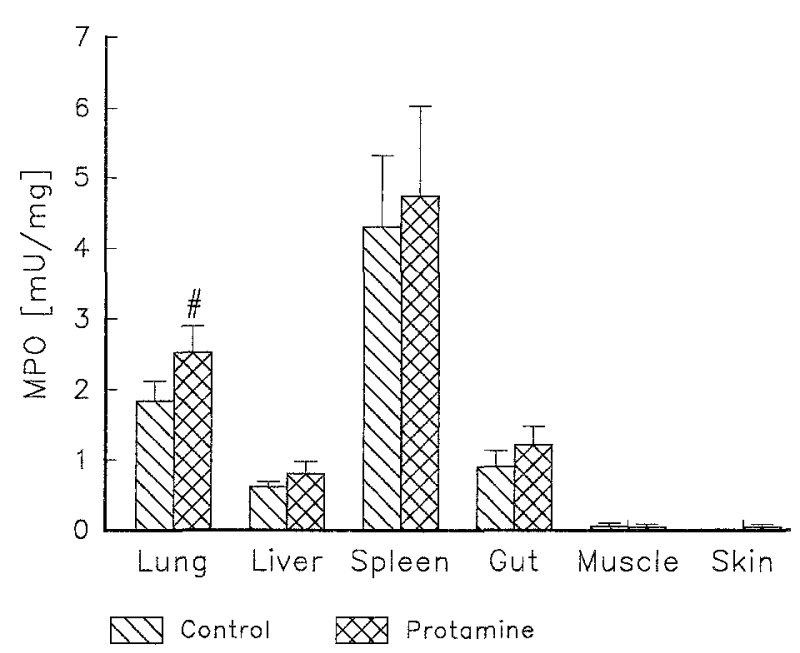

Fig. 5. The tissue concentration of MPO was determined in different organs of 20 separate hamsters 2 minutes after injection of saline solution (control, $n=10$ ) or of protamine (protamine, $n=10$ ). All data are mean \pm standard error of the mean; $\# p<0.05$, protamine group versus control group.

kopenia was consistently more pronounced in heparinized animals than in animals that received protamine alone, ${ }^{11,23,24}$ but it could not be abolished by complement depletion. ${ }^{26}$ Thus the transient leukopenia and activation of leukocyte-endothelial cell interaction by protamine seem to result from two distinct mechanisms: first, a direct effect of protamine on leukocytes and/or venular endothelial celis, which is enhanced by prior heparinization possibly through a second, indirect effect via mediators such as complement or thromboxane $\mathrm{A}_{2}$. The site of protamine injection had no influence on these parameters, which challenges the hypothesis that the initial site of cell activation would determine the site of leukocyte entrapment. ${ }^{7}$

We detected a biphasic response to protamine. First, within 30 seconds until 5 minutes after protamine, the leukocyte discharge concentration (i.e., the number of leukocytes per unit of volume flow in the observed venules) decreased by more than $75 \%$ whereas local rolling or adhesion of these leukocytes remained unaltered. At the nadir of this venous leukopenia ( 2 minutes after protamine) the MPO data indicate preferential margination of leukocytes in the lungs. Only in a second phase, about 4.5 to 13 minutes after protamine, when the number of leukocytes delivered to the venules under investigation again reached control values, did the number of rolling or adhering leukocytes increase simulta- 
neously. Obviously, the white blood cells transiently marginated in the lungs during the initial phase of the reaction. After release of the leukocytes from the pulmonary pool in the second phase, the leukocyte-endothelial cell interaction was increased in venules of skin-striated muscle and thus, possibly, throughout the body. The number of rolling leukocytes increased 2 to 5 minutes earlier than the number of sticking leukocytes. This observation is compatible with the hypothesis that leukocyte rolling is the first step in an adhesion cascade and precedes sticking and eventually emigration of the leukocyte. ${ }^{1}$

The molecular mechanisms involved in the increase of leukocyte-endothelial cell interaction by protamine cannot be identified from the present data. In publications before identification of adhesion molecules, surface charges on white blood cells and endothelial cells were thought to play a major role in leukocyte adhesiveness to endothelial cells or to artificial surfaces. ${ }^{27-29}$ The negative surface charges on leukocytes and endothelial cells would promote cell separation by electrostatic repulsion, thereby preventing both leukocyte-leukocyte and leukocyte-endothelial cell adherence. ${ }^{28}$ Protamine and other polycations reduce the negative surface charge and increase adhesion of leukocytes to endothelial cells. ${ }^{27,29}$ The hypothesis that protamineinduced leukocyte adhesiveness is charge mediated is compatible with the finding that leukocyte adhesiveness is reduced by heparin and numerous further negatively charged polysaccharides, ${ }^{4}$ but increased by protamine and by a variety of other cations. ${ }^{27}$

After heparin/protamine injection, the increased adhesiveness of leukocytes to venular endothelium might be due to the enhanced expression of specific adhesion molecules on leukocyte and endothelial cell surfaces. ${ }^{1-3}$ Considering the time that is required for activation or up-regulation of cell adhesion molecules, L-selectin and the $\beta_{2}$-integrin CD11b/ CD18 on leukocytes and P-selectin and intercellular adhesion molecule-1 on endothelial cells might possibly be involved in the rapid onset of leukocyte adhesion to endothelium after heparin/protamine injection. ${ }^{1,3} \mathrm{~L}$-selectin is constitutively expressed on leukocytes, whereas $\mathrm{P}$-selectin is prestored in endothelial cell granules. ${ }^{1} \mathrm{CD} 11 \mathrm{~b} / \mathrm{CD} 18$ appears to be activated within seconds by a variety of mediators including the complement fragments $\mathrm{C}_{3 \mathrm{a}}$ and $\mathrm{C}_{5 \mathrm{a}}{ }^{3}$ which are increased during the heparin/protamine reaction in human beings ${ }^{5,6}$ and sheep. ${ }^{8}$. In a recent study in pigs, CD18 expression on neutrophils in- creased by $23 \%$ after heparin/protamine injection, and the putative inhibitor of CD18 up-regulation, NPC 15669, attenuated both the leukopenia and the hemodynamic response. ${ }^{30}$ However, not only de novo expression but also avidity of preexpressed adhesion molecules may increase in response to a wide variety of stimuli. ${ }^{31}$ The observation that bivalent cations modulate avidity changes of $\beta_{2}$-integrins $^{31}$ suggests a possible role for the polycation protamine in this activation mechanism.

Identification of adhesion molecules involved in the protamine reaction in our hamster model by the respective antibody studies was not possible, because available antihuman or antirodent antibodies do not cross-react with the hamster receptor molecules.

In conclusion, we detected a biphasic pattern of leukocyte activation after protamine, which occurred independently of prior heparinization and the site (venous or arterial) of protamine administration: within the first minutes after protamine administration, leukocytes temporarily marginated in the lungs while blood leukocyte counts and microvascular discharge of leukocytes in the systemic circulation dropped by up to $70 \%$. Later on, leukocytes were released from the lungs, but interaction with peripheral venular endothelial cells was considerably increased. Although the molecular mechanisms of this reaction remain to be determined, in cardiac surgery the protamine-induced increased adhesiveness of leukocytes might contribute to white blood cell retention and myocardial damage in the reperfused heart after weaning from cardiopulmonary bypass.

\section{REFERENCES}

1. Carlos TM, Harlan JM. Leukocyte-endothelial adhesion molecules. Blood 1994;84:2068-101.

2. Springer TA. Adhesion receptors of the immune system. Nature 1990;346:425-34

3. Osborn L. Leukocyte adhesion to endothelium in inflammation. Can J Anaesth 1990;62:3-6.

4. Tangelder GJ, Arfors KE. Inhibition of leukocyte rolling in venules by protamine and sulfated polysaccharides. Blood 1991;77:1565-71.

5. Morel DR, Zapol WM, Thomas SJ, et al. C5a and thromboxane generation associated with pulmonary vaso- and broncho-constriction during protamine reversal of heparin. Anesthesiology 1987;66:597-604.

6. Hobbhahn J, Conzen PF, Habazettl H, Gutmann R, Kellermann W, Peter K. Heparin reversal by protamine in humanscomplement, prostaglandins, blood cells, and hemodynamics. J Appl Physiol 1991;71:1415-21.

7. Horrow JC. Protamine allergy. J Cardiothorac Vasc Anesth $1988 ; 2: 225-42$. 
8. Morel RD, Lowenstein E, Nguyenduy T, et al. Acute pulmonary vasoconstriction and thromboxane release during protamine reversal of heparin anticoagulation in awake sheep. Circ Res 1988:62:905-15.

9. Kreil E, Montalescot G, Greene E, et al. Nafamstat mesilate attenuates pulmonary hypertension in heparin-protamine reactions. J Appl Physiol 1989;67:1463-71.

10. Hobbhahn J, Conzen PF, Zenker B, Goetz AE, Peter K, Brendel W. Beneficial effect of cyclooxygenase inhibition on adverse hemodynamic responses after protamine. Anesth Analg 1988;67:253-60.

11. Conzen PF, Habazettl H, Gutmann R, et al. Thromboxane mediation of pulmonary hemodynamic responses after neutralization of heparin by protamine in pigs. Anesth Analg 1989;68:25-31.

12. Vollmar B, Conzen PF, Habazettl H, Yekebas E, Peter K. Heparin-protamine reactions in pigs: role of oxygen derived free radicals. J Appl Physiol 1993;74:2412-20.

13. Habazettl H, Conzen PF, Vollmar B, Yekebas E, Peter $\mathrm{K}$. Effect of leukopenia on pulmonary hypertension after heparin-protamine in pigs. J Appl Physiol 1992;73:44-9.

14. Hogg JC. Neutrophil kinetics and lung injury. Physiol Rev 1987;67:1249-95.

15. Wilson I, Gillinov AM, Curtis WE, et al. Inhibition of neutrophil adherence improves postischemic ventricular performance of the neonatal heart. Circulation 1993;88(Suppl): III372-9.

16. Lefer DJ, Shandelya SM, Serrano CVJ, Becker LC, Kuppusamy $\mathrm{P}$, Zweier JL. Cardioprotective actions of a monoclonal antibody against CD-18 in myocardial ischemia-reperfusion injury. Circulation 1993;88:1779-87.

17. Endrich B, Asaishi K, Goetz A, Messmer K. Technical report. A new chamber technique for microvascular studies in unanaesthetized hamster. Res Exp Med 1980;177:125-32.

18. Ley K, Gaethgens P. Endothelial, not hemodynamic, differences are responsible for preferential leukocyte rolling in rat mesenteric venules. Circ Res 1991;69:1034-41.

19. Zimmerhackl B, Parekh N, Brinkhus H, Steinhausen M. The use of fluorescent labeled erythrocytes for intravital investigation of flow and local hematocrit in glomerular capillaries in the rat. Int J Microcirc 1983;2:119-29.
20. Schierwagen C, Bylund-Fellenius A-C, Lundberg C. An improved method for quantification of tissue PMN accumulation measured by myeloperoxidase activity. J Pharmacol Meth 1990;23:179-86.

21. Moldow CF. Neutrophil endothelial interactions. In: Jaffe EA, editor. Biology of endothelial cells. Boston: Martinus Nijhoff, 1984:286-96.

22. Wakefield TW, Whitehouse TM, Stanley JC. Depressed cardiovascular function and altered platelet kinetics following protamine sulfate reversal of heparin activity. J Vasc Surg 1984;1:346-55.

23. Fehr $\mathbf{J}$, Rohr H. In vivo complement activation by polyanionpolycation complexes: evidence that C5a is generated intravascularly during heparin-protamine interaction. Clin Immunol Immunopathol 1983;29:7-14.

24. Montalescot G, Fischman AJ, Strauss HW, et al. Imaging the ovine heparin-protamine interaction with ${ }^{111}$ In-protamine. J Appl Physiol 1993;75:963-71.

25. Habazettl H, Conzen PF, Vollmar B, et al. Pulmonary hypertension after heparin-protamine-roles of left-sided infusion, histamine and platelet activating factor. Anesth Analg 1990;71:637-44.

26. Wakefield TW, Till GO, Lindblad B, Saenz N, Stanley JC. Complement depletion and persistent hemodynamic-hematologic responses in protamine-heparin reactions. J Surg Res 1988;45:320-6.

27. Bangham AD, Pethica BA, Seaman GVF. The charged groups at the interface of some blood cells. Biochem $\mathbf{J}$ 1958;69:12-8.

28. Harlan JM. Leukocyte-endothelial interactions. Blood 1985; 65:513-25.

29. Hoover RL, Folger R, Haering WA, Ware BR, Karnovsky MJ. Adhesion of leukocytes to endothelium: roles of divalent cations, surface charge, chemotactic agents and substrate. $J$ Cell Sci 1980;45:73-86.

30. Cho PW, Gillinov AM, Zehr KJ, Burch RM, Winkelstein JA, Cameron DE. Neutrophil activation mediates protamineinduced pulmonary hypertension. J Surg Res 1993;54:486-93.

31. Hogg N, Harvey J, Cabanas C, Landis RC. Control of leukocyte integrin activation. Am Rev Respir Dis 1993; 148(Suppl):55-9. 